\title{
A Case of Invasive Thymoma
}

Jon Geddes

Thomas Jefferson University

Follow this and additional works at: https://jdc.jefferson.edu/tmf

Part of the Neurology Commons

Let us know how access to this document benefits you

\section{Recommended Citation}

Geddes, Jon (2003) "A Case of Invasive Thymoma," The Medicine Forum: Vol. 4 , Article 10.

DOI: https://doi.org/10.29046/TMF.004.1.011

Available at: https://jdc.jefferson.edu/tmf/vol4/iss1/10

This Article is brought to you for free and open access by the Jefferson Digital Commons. The Jefferson Digital Commons is a service of Thomas Jefferson University's Center for Teaching and Learning (CTL). The Commons is a showcase for Jefferson books and journals, peer-reviewed scholarly publications, unique historical collections from the University archives, and teaching tools. The Jefferson Digital Commons allows researchers and interested readers anywhere in the world to learn about and keep up to date with Jefferson scholarship. This article has been accepted for inclusion in The Medicine Forum by an authorized administrator of the Jefferson Digital Commons. For more information, please contact: JeffersonDigitalCommons@jefferson.edu. 


\section{A Case of Invasive Thymoma}

Jon Geddes, MD, Resident, Department of Internal Medicine, 2000-2003

A 52 year-old man with a past medical history of an isolated seizure presented to the Veterans Affairs hospital complaining of weakness which was most prominent in the face and upper extremities. About 6 months prior to this admission he developed intermittent episodes of weakness when chewing and swallowing. He would often have to use his hands to close his jaw when eating or talking. He noticed that his voice had developed a nasal quality but he did not have slurred speech. He denied drooling, ptosis, cramping or muscle twitches. He was seen 6 months ago at another VA hospital where a neurologic workup was done. This included a cranial nerve EMG positive for denervation of cranial nerves, $\mathrm{R}$ arm and T- and L-spine. MRI and CT scans could not be done because the patient aspirated when supine. $\mathrm{He}$ was given a presumptive diagnosis of motor neuron disease, specifically bulbar ALS. At that time he was told he would need a PEG-feeding tube placed due to significant weight loss. The patient refused the feeding tube and did not follow up until again until 6 months later when the symptoms had worsened.

The patient's past medical history included an isolated seizure about 8 years ago. He had been taking phenytoin but it was discontinued several months ago after periodic negative EEG's. His family history was significant for a transient ischemic attack in his mother. There was no other family history of neurologic or systemic disorder. He had a 35 pack-year history of tobacco smoking. He also occasionally smoked marijuana. He quit drinking beer about a year ago and said he never drank heavily. The patient had a remote history of intravenous heroin use and was eager to undergo testing for HIV. He was employed as a roofer but quit recently because he was having to use his hands to hold his head up while working. There were no known occupational exposure to asbestos or chemicals.

The patient's heart, lung and abdominal exams were normal. On neurologic and musculoskeletal exam, the cranial nerves were intact. He had no tongue or facial fasciculations but did have bilateral temporal and masseter wasting. He had full strength throughout, but had slightly diminished vibratory sensation of the feet. There were no peripheral fasciculations or wasting. Deep tendon reflexes were $+2 / 4$ throughout. Cerebellar and Romberg exams were normal and there was no Babinski sign. The diagnsosis of ALS was questioned and the patient underwent further neurologic workup.

His metabolic panel, complete blood count and thyroid function tests were within normal limits, as were the B12 and folate levels. His HIV test was negative, while Hepatitis $\mathrm{C}$ antibody was positive with an undetectable viral load. Albumin was low at 2.7. The patient was able to lie supine for a brain MRI. The MRI and a chest radiograph were unremarkable. He underwent a videofluoroscopic swallowing study which revealed moderate oropharyngeal dysphagia with increased vallecular residue and impaired elevation of the larynx. There was no esophageal dysfunction. Pulmonary function tests showed a decrease in forced inspiratory flow@39\%.

He had an acetylcholine receptor antibody level was 3.62 $\mathrm{nmol} / \mathrm{L}$ (normal up to 0.4 ). His SPEP was near-normal with a slight polyclonal elevation (IgM and IgG). The IgA was slightly low. A noncontrast chest CT showed a lobulated mass in the anterior mediastinum measuring 5 $\mathrm{x} 3.8 \mathrm{~cm}$, extending from the sternum and abutting the SVC and aorta. (see Figure 1) The mass contained few calcifications. A lesion was seen in the anterior mediastinum just to the right of the sternum. It was pleural-based and measured $2 \times 0.8 \mathrm{~cm}$. Another pleuralbased lesion was seen in the right posterolateral chest. Finally, there were several smaller, nodular soft tissue lesions of similar density within the right lung. A CTguided biopsy was done on the anterior mediastinal lesion. It revealed a WHO Type B3 epithelial thymoma. (See Table 2).

While reviewing the CT scan for a possible substernal thymectomy, surgery requested that interventional radiology biopsy of one of the pleural lesions. The biopsy of the pleural-based posterolateral chest lesion (see Figure 2) was also consistent with epithelial thymoma. CT scans of the neck, abdomen and pelvis showed no evidence of other metastases. Since thymectomy would not be curative for a metastatic lesion the patient was referred to oncology where he was started on chemotherapy with 
cisplatin, cyclophosphamide and adriamycin. He was also started on pyridostigmine for control of the myasthenia gravis. Chemotherapy was uncomplicated but a few weeks later the patient was admitted for community-acquired pneumonia and diarrhea. He was started on the appropriate antibiotic regimen and his pyridostigmine was withheld for diarrhea. During this acute illness the patient was so profoundly weak he had to constantly lean forward in bed to allow saliva to drain. Just as the decision was made to move the patient to an intensive care unit and electively intubate him for airway protection, his condition began to improve. He was once again able to swallow and within 3 days he had regained almost full strength. At this point he was a few weeks out from chemotherapy and a follow-up chest CT showed a marked decrease in the size of the patient's mediastinal mass (and pleural/lung masses).

\section{Discussion}

This patient was initially diagnosed with motor neuron disease, specifically bulbar amyotrophic lateral sclerosis. It is difficult to tell why the diagnosis of myasthenia gravis was not made initially. The patient had less than optimal follow up and the clinical picture was further complicated because the patient's report of symptom onset at the time of a neck injury several years before. The physicians who first saw him must have wondered whether his fall from a ladder was a cause or result of his symptoms. Furthermore, the patient was taking his anticonvulsant medication eratically and his desire to taper off his anticonvulsant was a priority.

Thymomas are the most common primary anterior mediastinal tumor and account for $15-20 \%$ of all mediastinal masses 1 . Thymomas are derived from epithelial thymus cells with varying degrees of atypia, along with normal lymphocytes. These tumors should be distinguished from thymomas involving lymphomas, germ cell tumors, carcinoid tumors a small cell cancer. Thymomas are associated with many paraneoplastice syndromes, the most common of which is myasthenia gravis, which is seen in about 30\% of patients with thymomas. Other paraneoplastic syndromes include pure red cell aplasia, acquired hypogamaglobulinemia and connective tissue disorders such as Sjogren's syndrome, myocarditis, dermatomyositis, SLE and rheumatoid arthritis.

About $15 \%$ of myasthenia gravis patients have thymomas. This has resulted in widespread screening for thymoma in $\mathrm{MG}$ patients. In other cases, thymomas are usually picked up by routine CXR or when patients present with symptoms secondary to mass effects, such as coughing, shortness of breath or chest pain.

There are several classification systems for thymomas. The Lattes/Bernatz, Rosai/Levine and Muller-Mermelink are based on microscopic appearance alone while the more commonly used Masaoka system is based on degree of invasion. A fourth classification system proposed by the World Health Organization was used with this patient. There is controversy regarding the most useful classification system in terms of predicting survival. Several of the studies used to develop these classification systems involved small numbers of patients. From a practical standpoint, the degree of invasiveness.

While it has often been reported that myasthenia gravis portends a worse prognosis in patients with thymoma, a more recent study patients with thymomas and myasthenia gravis appear to have a significantly better overall prognosis that those without myasthenia symptoms. It would appear that patients with myasthenia symptoms present earlier in the course of disease and the thymoma was caught at an earlier stage. However, one series has shown that this is not the case. Also, patients with myasthenia gravis are more likely to follow-up with their doctors and get better care for all of their medical problems. It has been shown that most patients with thymomas (invasive or noninvasive) tend to die of medical problems other than the thymoma. A third possible explanation was myasthenia patients seem to do better may be because some of them get treated with steroids, which can lead to involution of thymomas. Interestingly, while myasthenia appears to be a good independent predictor of survival, resection or "cure" of thymomas typically does not affect the myasthenia symptoms. The most significant independent predictor of survival is surgical resectability at initial presentation. Other independent risk factors for improved survival are 
absence of advanced pathologic stage (per the Lattes/Bernatz classification) and age $<57$ yrs. ${ }^{1}$

Treatment for thymoma is generally involves surgical resection, with a recurrence rate of about $2 \%$ for encapsulated tumors and about $20-40 \%$ for invasive lesions. Preoperative radiation therapy does not generally improve survival, but adjuvant postoperative therapy is considered the standard of care for completely or incompletely resected stage III or stage IV thymomas. For metastatic thymoma, this is generally not possible chemotherapy should be considered. Candidates for chemotherapy include about $1 / 3$ of patients with invasive thymoma and all patients with stage IV disease. The usual regimen is cisplatin, doxorubicin and cyclophosphamide (PAC). Chemotherapy is followed by radiation and in one study this resulted in a 52\% five year survival rate.,3

In summary, thymoma should be considered in any patient with myasthenia gravis. The most important predictor of survival is surgical respectability at initial presentation. Finally, the presence myasthenia gravis is a predictor of improved survival in thymoma.

\section{References}

1 Wilkins KB, et al. Clinical and Pathologic Predictors of Survival in Patients With Thymoma. Annals of Surgery. October 1999; Vol 230, No 4

2 Curran WJ, Kornstein MJ, Brooks JJ, etal.: Invasive thymoma: the role of mediastinal irradiation following complete or incomplete surgical resection. Journal of Clinical Oncology 6(11):1722-1727, 1988.

3 Loehrer PJ, Chen M, Kim K, et al: Cisplatin, doxorubicin and cyclophosphamide plus thoracic radiation therapy for limited-stage unresectable thymoma: an intergroup trial. Journal of Clinical Oncology 15(9): 3093-3099, 1997

Figure 1. Noncontrast chest CT showing mass in anterior mediastinum

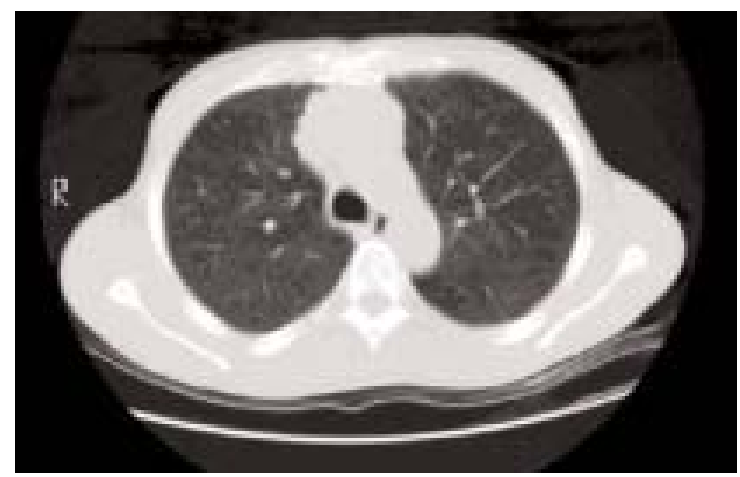

Table 1. Masaoka Classification

\begin{tabular}{ll}
\hline Stage & Extent of disease \\
\hline I & Totally encapsulated \\
\hline II & $\begin{array}{l}\text { Capsular invasion and/or invasion } \\
\text { into surrounding fat or pleura }\end{array}$ \\
\hline III & $\begin{array}{l}\text { Invasion into organs } \\
\text { (pericardium, lung, great vessels) }\end{array}$ \\
\hline Iva & Pleural or pericardial implants \\
\hline IVb & Hematogenous metastases \\
\hline
\end{tabular}

Table 2. WHO Classification

\begin{tabular}{ll}
\hline Histological Types & Characterization \\
\hline $\begin{array}{l}\text { WHO Classification } \\
\text { ofThymic Epithelial }\end{array}$ & $\begin{array}{l}\text { This system is based upon the } \\
\text { morphology of the epithelial cells } \\
\text { as well as the lymphocyte to } \\
\text { epithelial cell ratio }\end{array}$ \\
\hline Type A & $\begin{array}{l}\text { Homogeneous population of neoplastic } \\
\text { epithelial cells having spindle/oval shape, } \\
\text { lacking nuclear atypia, and accompanied by } \\
\text { few or no non-neoplastic lymphocytes }\end{array}$ \\
\hline Type AB & $\begin{array}{l}\text { Foci having the features of type A admixed } \\
\text { with foci rich in lymphocytes; the segregation } \\
\text { of the two patterns can be sharp and distinct }\end{array}$ \\
\hline Type B1 & $\begin{array}{l}\text { Resembles the normal functional thymus by } \\
\text { combininglarge expanses with an appearance } \\
\text { practically indistinguishable from normal } \\
\text { thymic cortex with areas resembling thymic } \\
\text { medulla }\end{array}$ \\
\hline Type B2 & $\begin{array}{l}\text { Neoplastic epithelial component appears as } \\
\text { scattered plump cells with vesicular nuclei } \\
\text { and distinct nucleoli among a heavy } \\
\text { population of lymphocytes; perivascular } \\
\text { spaces are common }\end{array}$ \\
\hline Type C & $\begin{array}{l}\text { Predominately composed of epithelial cells } \\
\text { having round or polygonal shape and } \\
\text { exhibiting mild atypia admixed with a minor } \\
\text { component of lymphocytes, foci of } \\
\text { squamous metaplasia and perivascular spaces } \\
\text { are common }\end{array}$ \\
\hline Thymic carcinoma \\
\hline
\end{tabular}

Figure 2. CT-guided biopsy of pleural-based mass

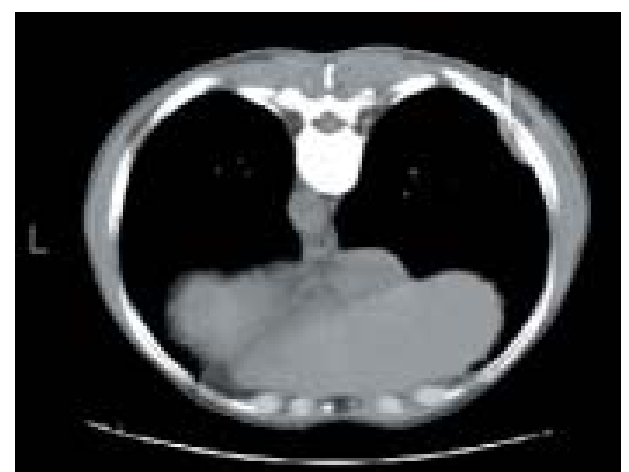


The Medicine Forum, Vol. 4 [2003], Art. 10

Notes 